\title{
A Depletable Pool of Adenosine in Area CA1 of the Rat Hippocampus
}

\author{
Tim Pearson, ${ }^{2}$ Feruza Nuritova, ${ }^{2}$ Darren Caldwell, ${ }^{2}$ Nicholas Dale, ${ }^{1}$ and Bruno G. Frenguelli ${ }^{2}$ \\ ${ }^{1}$ Department of Biological Sciences, University of Warwick, Coventry CV4 7AL, United Kingdom, and ${ }^{2}$ Department of \\ Pharmacology and Neuroscience, University of Dundee, Ninewells Hospital and Medical School, Dundee DD1 9SY, \\ United Kingdom
}

\begin{abstract}
Adenosine plays a major modulatory and neuroprotective role in the mammalian CNS. During cerebral metabolic stress, such as hypoxia or ischemia, the increase in extracellular adenosine inhibits excitatory synaptic transmission onto vulnerable neurons via presynaptic adenosine $A_{1}$ receptors, thereby reducing the activation of postsynaptic glutamate receptors. Using a combination of extracellular and whole-cell recordings in the CA1 region of hippocampal slices from 12- to 24-d-old rats, we have found that this protective depression of synaptic transmission weakens with repeated exposure to hypoxia, thereby allowing potentially damaging excitation to both persist for longer during oxygen deprivation and recover more rapidly on reoxygenation. This phenomenon is unlikely to involve $A_{1}$ receptor desensitization or impaired nucleoside transport. Instead, by using the selective $A_{1}$ antagonist 8-cyclopentyl-1,3-
\end{abstract}

Extracellular adenosine in the CNS increases during pathological stimuli such as head injury (Nilsson et al., 1990; Headrick et al., 1994), epileptic seizures (Winn et al., 1980; Dunwiddie, 1999), and hypoxia/ischemia (Berne et al., 1974; Rudolphi et al., 1992; Sweeney, 1997; Von Lubitz, 1999). The increase in extracellular adenosine inhibits glutamate release via presynaptic adenosine $\mathrm{A}_{1}$ receptors (Fowler, 1989; Katchman and Hershkowitz, 1993; Zhu and Krnjevic, 1993; Pearson and Frenguelli, 2000). In addition, simultaneous activation of postsynaptic $\mathrm{A}_{1}$ receptors activates a potassium conductance leading to membrane hyperpolarization, thereby intensifying the magnesium block of the NMDA subtype of glutamate receptor (Erdemli et al., 1998; Von Lubitz, 1999). Together, these actions exert a powerful neuroprotective "retaliatory" (Newby, 1984) influence during traumatic or metabolic stress.

Manipulations that increase extracellular adenosine, such as adenosine uptake inhibition (Gidday et al., 1995), inhibition of adenosine metabolizing enzymes (Phillis and O'Regan, 1989; Miller et al., 1996; Jiang et al., 1997), or activation of $A_{1}$ receptors by exogenous $\mathrm{A}_{1}$ agonists (Rudolphi et al., 1992; Sweeney, 1997; Von Lubitz, 1999; de Mendonca et al., 2000) are all neuropro-

\footnotetext{
Received Aug. 21, 2000; revised Jan. 16, 2001; accepted Jan. 19, 2001.

We are grateful to The Wellcome Trust, The Scottish Hospital Endowment Research Trust, Tenovus (Tayside), The Anonymous Trust (Dundee), and the Royal Society for financial support. B.G.F. is a Caledonian Research Foundation Fellow. We thank John Bell (Sycopel International Ltd.) for help with the design of the adenosine biosensors.

Correspondence should be addressed to Dr. B. G. Frenguelli, Department of Pharmacology and Neuroscience, University of Dundee, Ninewells Hospital and Medical School, Dundee DD1 9SY, UK. E-mail: b.frenguelli@dundee.ac.uk. Copyright (C) 2001 Society for Neuroscience 0270-6474/01/212298-10\$15.00/0
}

dipropylxanthine and a novel adenosine sensor, we demonstrate that adenosine production is reduced with repeated episodes of hypoxia. Furthermore, this adenosine depletion can be reversed at least partially either by the application of exogenous adenosine, but not by a stable $A_{1}$ agonist, $N^{6}$-cyclopentyladenosine, or by endogenous means by prolonged ( $2 \mathrm{hr}$ ) recovery between hypoxic episodes. Given the vital neuroprotective role of adenosine, these findings suggest that depletion of adenosine may underlie the increased neuronal vulnerability to repetitive or secondary hypoxia/ischemia in cerebrovascular disease and head injury.

Key words: adenosine; hypoxia; ischemia; sensor; depletion; replenishment; glutamate; hippocampus; head injury; TBI; stroke; TIA; neuroprotection; adenosine deaminase; nucleoside phosphorylase; xanthine oxidase

tective. Conversely, antagonism of $\mathrm{A}_{1}$ receptors (Rudolphi et al., 1992; Sweeney, 1997; Von Lubitz, 1999; de Mendonca et al., 2000) and increased metabolism of extracellular adenosine (Donaghy and Scholfield, 1994; Sweeney, 1997; de Mendonca et al., 2000) increases neuropathology.

Despite the protective influence of endogenous adenosine, repeated exposure to brief hypoxia/ischemia, over the period of a few hours, results in an exacerbation of neuronal damage even if the episodes are of such short duration (2-3 min) that they cause no damage when administered in isolation. No explanation for this phenomenon has been advanced despite it being a consistent observation in studies of the effects of cerebral ischemia (Tomida et al., 1987; Kato et al., 1989) and head injury (Jenkins et al., 1989; Nawashiro et al., 1995). These observations imply the loss of a homeostatic mechanism that leaves the CNS vulnerable to subsequent hypoxia/ischemia. Indeed, it is clear from the study of head-injured humans that secondary hypoxia/ischemia caused by depression of central respiratory centers or occlusion or damage of the cerebral vasculature is a major cause of neuropathology and death (Blumbergs, 1997). Furthermore, in compromised neonates, epileptic seizures are frequently associated with periods of cerebral hypoxia (Volpe, 1995).

In this study we have examined the effects of repeated exposure to hypoxia on excitatory synaptic transmission in CA1 neurons of the hippocampus, widely regarded as among the most vulnerable in the mammalian CNS to disruptions in nutrient supply. We have shown that the adenosine-dependent depression of excitatory synaptic transmission during hypoxia is weakened by previous exposure to hypoxia. Direct measurement of adenosine release during hypoxia revealed reduced production of adenosine. 
However, by giving exogenous adenosine or prolonged interepisode recovery intervals, the sensitivity of synaptic transmission to hypoxia can be partially restored. Our data suggest a previously undescribed vulnerability of adenosine production and provide a plausible explanation for the increased sensitivity of the CNS to the repeated insults commonly experienced in various human neurological disorders, such as cerebrovascular disease or after head injury.

\section{MATERIALS AND METHODS}

Slice preparation. Sprague Dawley rats of either sex, aged 12-24 d, were killed by cervical dislocation in accordance with Schedule 1 of the UK Government Animals (Scientific Procedures) Act 1986. After decapitation, the brain was rapidly removed and placed in ice-cold artificial CSF (aCSF) containing $11 \mathrm{mM} \mathrm{Mg}^{2+}$ wherein $400 \mu \mathrm{m}$ transverse hippocampal slices were cut with a Vibratome (IntraCel, Royston, Herts, UK) as described previously (Dale et al., 2000). Slices were placed in an incubation chamber comprising a nylon mesh within a beaker of continuously circulating, oxygenated $\left(95 \% \mathrm{O}_{2} / 5 \% \mathrm{CO}_{2}\right)$ standard aCSF $\left(1 \mathrm{mM} \mathrm{Mg}^{2+}\right)$ and kept at room temperature for at least $1 \mathrm{hr}$ before use. The composition of the standard aCSF solution was (in $\mathrm{mm}$ ): $\mathrm{NaCl} \mathrm{124,} \mathrm{KCl} 3$, $\mathrm{CaCl}_{2} 2, \mathrm{NaHCO}_{3} 26, \mathrm{NaH}_{2} \mathrm{PO}_{4} 1.25$, D-glucose $10, \mathrm{MgSO}_{4} 1, \mathrm{pH} 7.4$ with $95 \% \mathrm{O}_{2} / 5 \% \mathrm{CO}_{2}$.

Extracellular recording. A single slice was transferred to a recording chamber, fully submerged in aCSF, and perfused at $6 \mathrm{ml} / \mathrm{min}\left(32-34^{\circ} \mathrm{C}\right)$. A theta glass $(<5 \mathrm{M} \Omega)$ or twisted Teflon-coated tungsten bipolar stimulating electrode $(\sim 100 \mu \mathrm{m}$ in diameter) positioned in stratum radiatum was used to stimulate the Schaffer collateral commissural pathway at 15 sec intervals. The stimulus intensity $(\sim 30-50 \%$ of maximum) was subthreshold for population spike activation. Extracellular recordings of the evoked field EPSPs (fEPSPs) were made from stratum radiatum with aCSF-filled glass microelectrodes $(<2 \mathrm{M} \Omega)$. Electrical signals were acquired at $10 \mathrm{kHz}$, filtered at $1 \mathrm{~Hz}-3 \mathrm{kHz}$, and recorded to a Pentium computer using "LTP" data acquisition and analysis software (courtesy of Dr. Bill Anderson and Professor Graham Collingridge, Bristol University, UK; www.ltp-program.com).

Measurement of extracellular adenosine and simultaneous extracellular recording. A novel adenosine sensor was used to measure directly the release of adenosine during hypoxia (Dale, 1998; Dale et al., 2000). Briefly, the sensor (Sycopel International Ltd., Jarrow, Tyne \& Wear, UK) uses an enzymic cascade that sequentially converts adenosine to inosine (adenosine deaminase; EC 3.5.4.4) to hypoxanthine (nucleoside phosphorylase; EC 2.4.2.1) to uric acid and hydrogen peroxide (xanthine oxidase; EC 1.1.3.22). The hydrogen peroxide is polarized on $50 \mu \mathrm{m}$ platinum wires located within the twin barrels of the sensor. The twin barrels, one of which lacks adenosine deaminase, allowed differential measurements to be made, increasing the specificity of the signal for adenosine. The sensor (overall width $\sim 500 \mu \mathrm{m}$ ) was placed on the surface of area CA1 with the recording electrode within $200 \mu \mathrm{m}$ of the sensor. Within each experiment, frequent calibration of the sensor via bath-application of exogenous adenosine (usually $2 \mu \mathrm{M}$ ) allowed conversion of the sensor output (in nanoamperes) to units of adenosine concentration (cf. Dale et al., 2000). Calibration was performed either before or shortly after a hypoxic episode under identical extracellular ionic conditions. The output of the sensor was recorded on a chart recorder. Field EPSPs were evoked and recorded with LTP software and displayed on the second channel of the chart recorder.

Whole-cell patch clamp. Recordings from CA1 pyramidal neurons were made under visual guidance (oblique illumination of slice) with a Carl Zeiss Axioskop FS upright microscope (Carl Zeiss, Welwyn Garden City, UK). Patch electrodes (4-8 $\mathrm{M} \Omega$ ) were filled with (in $\mathrm{mM}$ ): $\mathrm{CeMeSO}_{3}$ 100, HEPES 40, NaATP 2, NaGTP 0.3, $\mathrm{MgCl}_{2}$ 5, glutathione 5, EGTA 0.2, QX314 5. An aCSF-filled, glass stimulating electrode was placed in stratum radiatum $\sim 50 \mu \mathrm{m}$ from the cell body layer and 50-100 $\mu \mathrm{m}$ from the patched cell. EPSCs (in the presence of 50-100 $\mu \mathrm{M}$ picrotoxin or $10 \mu \mathrm{M}$ bicuculline) were sampled at $10 \mathrm{kHz}$, filtered at 1 $\mathrm{kHz}$, and recorded with an Axopatch-1D amplifier (Axon Instruments, Foster City, CA). Data acquisition was under the control of LTP software. EPSCs were evoked at $15 \mathrm{sec}$ intervals, and four events (1 min of data) were averaged. Small voltage steps $( \pm 5 \mathrm{mV})$ were evoked before an EPSC to monitor membrane and series resistance.

Induction of hypoxia. In all experiments, hypoxia was induced by the substitution of standard aCSF with identical aCSF pre-equilibrated with
$95 \% \mathrm{~N}_{2} / 5 \% \mathrm{CO}_{2}$ as described previously (Frenguelli, 1997; Dale et al., 2000). This manipulation reduced bath oxygen tension from $\sim 80-90 \%$ saturation to $<10 \%$, as measured by a Diamond General oxygen microelectrode (IntraCel). The duration of hypoxia varied between 2.25 and $40 \mathrm{~min}$, and up to five hypoxic episodes were given in any one experiment. Tissue was exposed to a drug for at least $30 \mathrm{~min}$ before the induction of hypoxia.

Chemicals. Chemicals used in the aCSF were supplied by BDH (Lutterworth, Leics, UK). Adenosine was supplied by both RBI (Poole, Dorset, UK) and Sigma-Aldrich (Poole, Dorset, UK). Adenosine deaminase (EC 3.5.4.4), nucleoside phosphorylase (EC 2.4.2.1), xanthine oxidase (EC 1.1.3.22), cesium methanesulfonate $\left(\mathrm{CeMeSO}_{3}\right)$, HEPES, EGTA, NaATP, NaGTP, $\mathrm{MgCl}_{2}$, and glutathione were obtained from Sigma. $S$-(4-nitrobenzyl)-6-thioinosine (NBTI), dipyridamole (DIPY), 8-cyclopentyl-1,3-dipropylxanthine (DPCPX), $\mathrm{N}^{6}$-cyclopentyladenosine ( $\left.{ }^{6} \mathrm{CPA}\right)$, and lidocaine $N$-ethyl bromide (QX-314) were all supplied by RBI. DPCPX and DIPY were dissolved in ethanol; the final concentration of vehicle was $0.001-0.02$ and $0.05 \%$, respectively.

Data analysis. The effects of hypoxia on synaptic transmission were quantified in terms of the time taken for hypoxia to depress synaptic transmission to $50 \%\left(t_{50}\right)$ of baseline values. This figure was arrived at by interpolation by eye, for the time taken for transmission to decay to $50 \%$ (extracellular recording), or by sometimes fitting a single decaying exponential to the decay phase of transmission (whole-cell experiments). $T_{50}$ values of repeated synaptic depressions from individual experiments were pooled into groups and compared using, where appropriate, paired $t$ test, unpaired $t$ test, or as otherwise indicated. Significance was noted at the level of $p<0.05$. Data are presented as mean \pm SEM.

\section{RESULTS}

\section{Hypoxia rapidly and reversibly depresses excitatory synaptic transmission in area CA1 via the activation of presynaptic adenosine $A_{1}$ receptors}

Exposure of hippocampal slices to hypoxia resulted in a rapid depression of the fEPSP [ $50 \%$ depression in $80 \pm 2 \mathrm{sec}(n=165)$ and $96.4 \pm 1.5 \%$ depression at $5 \mathrm{~min}(n=114)]$, which was greatly attenuated by the selective adenosine $\mathrm{A}_{1}$ antagonist DPCPX [200 $\mathrm{nM} ; 23.5 \pm 4.5 \%$ depression at $5 \mathrm{~min}(n=5)]$ (Fig. 1$)$.

\section{The hypoxic depression of synaptic transmission is delayed by subsequent exposure to hypoxia}

After exposure to hypoxia and subsequent recovery of transmission, slices were re-exposed to a second hypoxic episode. We consistently observed greater resistance of synaptic transmission to the second hypoxic episode (Fig. 2) that manifested as a slowing of the rate of decay of the fEPSP during hypoxia. We termed this "conditioning" and quantified it as the difference $\left(\Delta t_{50}\right)$ between the time to $50 \%$ depression $\left(t_{50}\right)$ of the first $\left(t_{50(1)}\right)$ and second $\left(t_{50(2)}\right)$ hypoxic episodes.

Brief hypoxic episodes (2.25 min) (Fig. $2 B$ ) cause an incomplete depression $(85.0 \pm 4.1 \% ; n=11)$ of the fEPSP yet still resulted in significant conditioning $\left(\Delta t_{50}=12 \pm 3 \mathrm{sec} ; n=11\right.$; paired $t$ test, $p<0.002$ ). Prolonging the duration of the first hypoxic episode progressively increased the extent of conditioning and reduced the efficacy of hypoxia in depressing synaptic transmission (Fig. 2B). For example, an initial 10 min hypoxic episode induced conditioning of $48 \pm 2 \sec (n=94)$. This resulted in transmission being depressed by only $13.9 \pm 2.4 \%$ during the second hypoxic episode at a time $(1.25 \mathrm{~min})$ at which the fEPSP had been depressed by $50.1 \pm 4.1 \%$ during the first. At the longest time point tested, an initial hypoxic episode of $40 \mathrm{~min}$ duration resulted in conditioning of $78 \pm 4 \sec (n=27)$. The extent of conditioning, when plotted against the duration of the initial hypoxic episode, appeared to achieve an asymptote. Indeed, such a relation could be fitted by a simple exponential function $\Delta t_{50}=T_{\infty}\left(1-e^{-t / \tau}\right)$, where $T_{\infty}$, the maximal amount of 


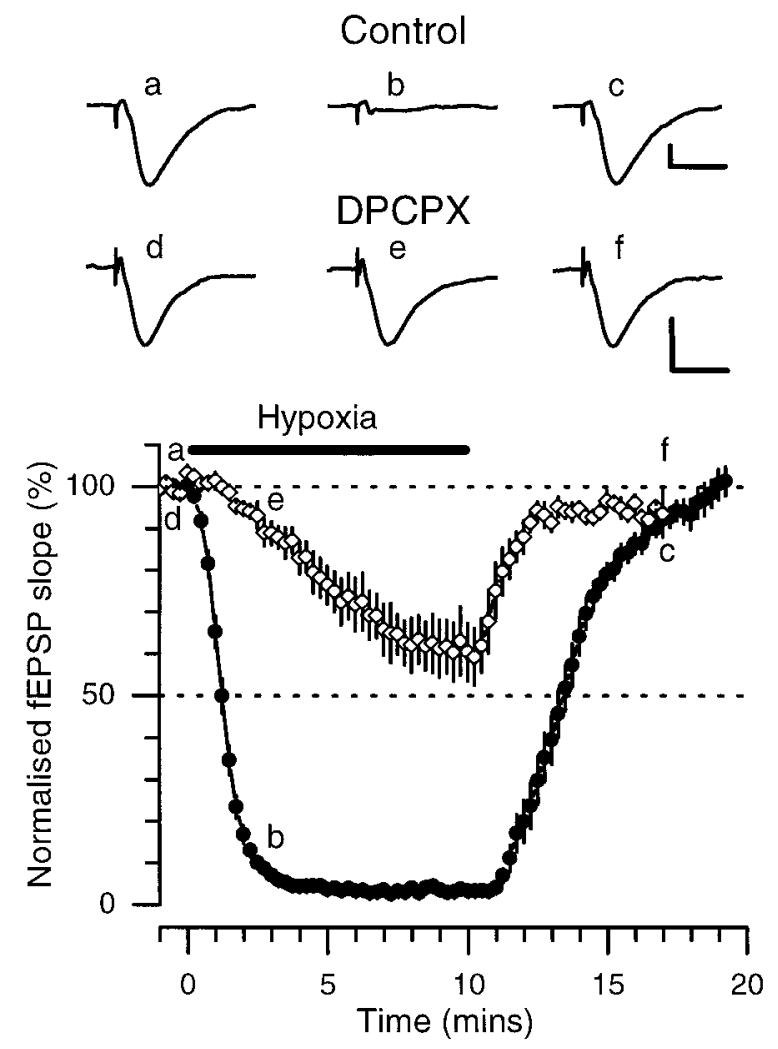

Figure 1. Role of adenosine $\mathrm{A}_{1}$ receptors in the hypoxic depression of excitatory synaptic transmission. Pooled data, normalized to the prehypoxic fEPSP slope, for control $(\bullet ; n=24)$ and $200 \mathrm{~nm}$ DPCPX-treated $(\diamond ; n=5)$ slices showing the effect of a single 10 min hypoxic episode (denoted by the black bar). Inset shows typical fEPSPs taken at the time points indicated, before $(a, d)$, during $(b, e)$, and after $(c, f)$ the hypoxic episode: control $(a-c) ; 200 \mathrm{nM}$ DPCPX $(d-f)$. Note the differences in the fEPSPs at time points $(b)$ and after $(e) 3$ min of hypoxia reflecting the $\mathrm{A}_{1}$ receptor-dependence of the hypoxic depression of the fEPSP. Calibration: $10 \mathrm{msec}, 0.4 \mathrm{mV}$.

conditioning, was $80.2 \mathrm{sec}$, and $\tau$, the time constant of conditioning, was $725 \mathrm{sec}$.

In addition, synaptic transmission recovered faster during the second and subsequent hypoxic episodes. For example, $2.5 \mathrm{~min}$ after the return to normoxia, synaptic transmission had recovered to $29.0 \pm 8.3 \%$ of control after the first 10 min hypoxic episode. At the same time point, transmission had recovered to $60.6 \pm$ $8.2 \%$ of control after the second 10 min hypoxic episode (paired $t$ test, $p=0.01 ; \mathrm{n}=9$; data not shown).

To ensure that conditioning did not reflect some timedependent change in the integrity of the hippocampal slice, such as the gradual loss of adenosine, we placed slices in the recording chamber and measured synaptic transmission for $\sim 90 \mathrm{~min}$ beyond the initial stabilization period of $\sim 30 \mathrm{~min}$. A gradual loss of adenosine would be expected to result in a longer $t_{50}$ value. However, after this protracted incubation period, $t_{50}$ measured $82 \pm 4 \sec (n=15)$ and was not significantly different (unpaired $t$ test, $p>0.3$ ) from interleaved controls given a 30 min stabilization period $\left(t_{50}=77 \pm 3 \mathrm{sec} ; n=26\right)$. Furthermore, the period of incubation had no influence (unpaired $t$ test, $p>0.4$ ) on the extent of conditioning after an initial 10 min hypoxic episode $\left[\Delta t_{50}=42 \pm 3 \mathrm{sec}(n=26)\right.$ and $37 \pm 4 \sec (n=15)$ for 30 and 90 min incubation, respectively].
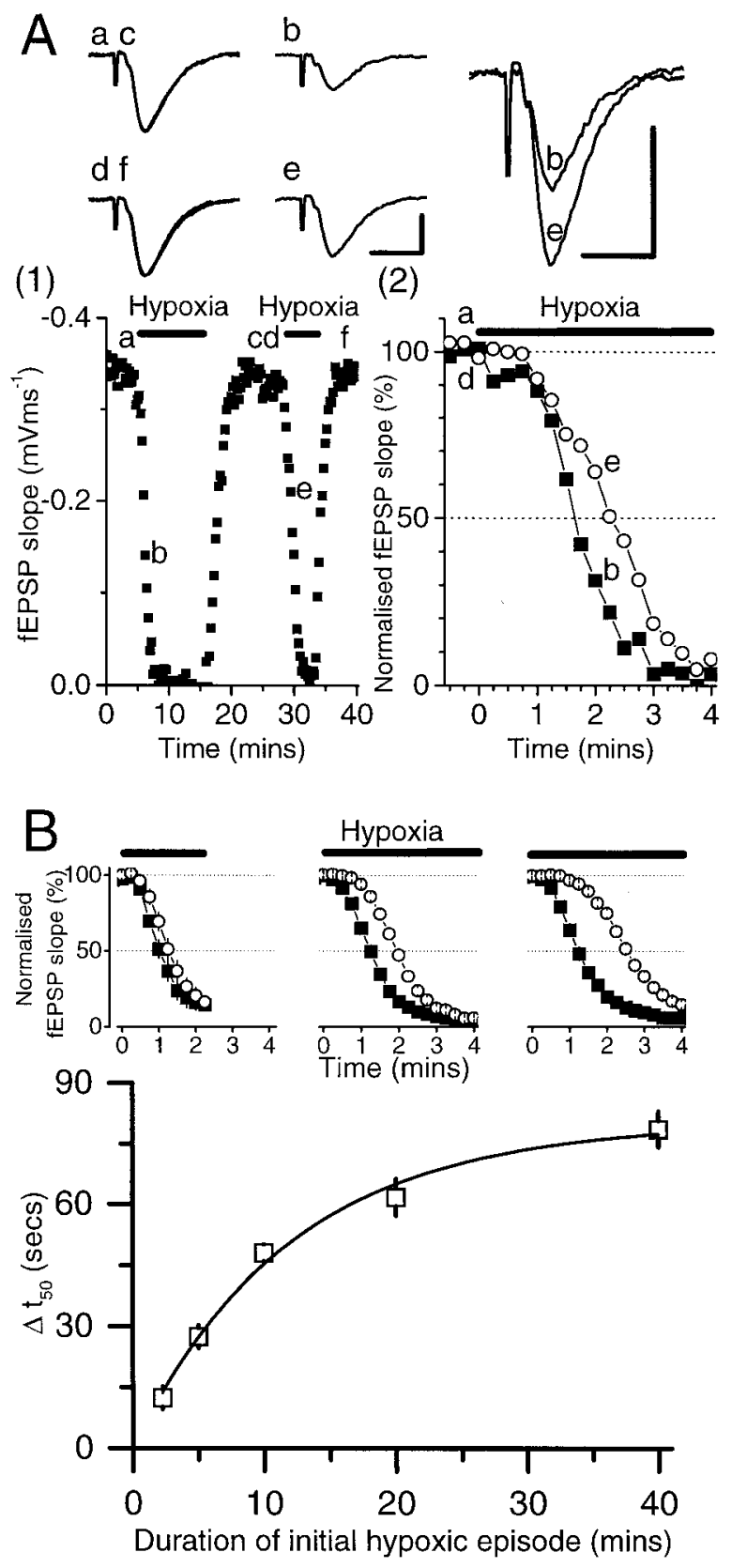

Figure 2. Exposure to hypoxia results in reduced sensitivity of synaptic transmission to subsequent hypoxia. $A$, A typical experiment in which two sequential hypoxic episodes were given to the same slice. $A(1)$ shows fEPSP slope versus time. Labeled at time points $a$ through $f$ are fEPSPs (inset above, stimulus artifacts are truncated) before $(a, d)$, during $(b, e)$, and after $(c, f)$ two sequential hypoxic episodes (10 and $5 \mathrm{~min}$, respectively). $A(2)$, Superimposition of normalized data from the first 4 min of each hypoxic episode ( $\square$, first episode; $\bigcirc$, second episode). Notice the resistance (conditioning) of the fEPSP to hypoxia during the second episode. The superimposed fEPSPs $(b, e)$, both taken 2 min into the hypoxic episode, highlight this apparent acquired resistance to the effects of hypoxia. Calibration: 10 $\mathrm{msec}, 0.4 \mathrm{mV}$. B, Conditioning depends on the duration of the first hypoxic episode. Insets show pooled normalized data of the influence of the duration of the first hypoxic episodes ( $\square)$ of (from left to right) $2.25(n=11), 10$ $(n=24)$, and $40 \mathrm{~min}(n=21)$ on the decay of the fEPSP during the second hypoxic episode $(\bigcirc)$. Graph shows dependence of conditioning, expressed as the difference between the time to $50 \%$ depression of the fEPSP of the first and second episodes $\left(\Delta t_{50}: 2.25 \mathrm{~min}, n=11 ; 5 \mathrm{~min}, n=32 ; 10 \mathrm{~min}, n=\right.$ 94; $20 \mathrm{~min}, n=10$; $40 \mathrm{~min}, n=27$ ) on the duration of initial hypoxic episode. Line through points follows the equation given in Results and gives a time constant of conditioning of 725 sec. 


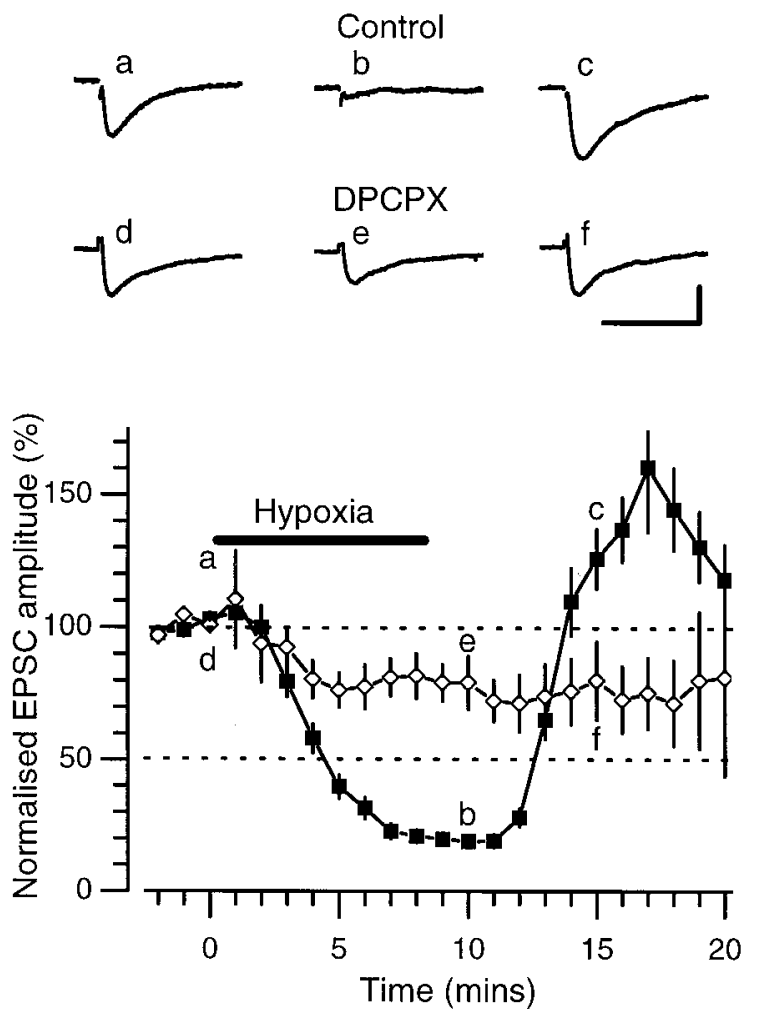

Figure 3. Role of adenosine $\mathrm{A}_{1}$ receptors in the hypoxic depression of excitatory synaptic transmission under whole-cell voltage-clamp conditions. Pooled data, normalized to the prehypoxic EPSC amplitude, for control $(\square ; n=70)$ and $200 \mathrm{~nm}$ DPCPX-treated $(\diamond ; n=14)$ slices show the effect of a single 10 min hypoxic episode (denoted by the black bar). Inset shows typical EPSCs taken at the time points indicated, before $(a$, $d$ ), during $(b, e)$, and after $(c, f)$ the hypoxic episode: control $(a-c) ; 200 \mathrm{nM}$ DPCPX $(d-f)$. Note the differences in the fEPSPs at time points $b$ and $e$ after $10 \mathrm{~min}$ of hypoxia reflecting the $A_{1}$ receptor-dependence of the hypoxic depression of the EPSC. Calibration: $40 \mathrm{msec}, 50 \mathrm{pA}$.

\section{Conditioning is observed under whole-cell voltage clamp}

To test whether conditioning occurred at the level of single cells, we performed whole-cell voltage-clamp recordings from CA1 neurons. One neuron per slice was exposed to two sequential 5 or 10 min hypoxic episodes. The hypoxic depression of the EPSC was greatly attenuated by DPCPX (200 nM; $20.7 \pm 10.0 \%$ depression after 10 min of hypoxia; $n=14$ ) (Fig. 3) compared with the hypoxic depression in the absence of DPCPX $(81.0 \pm 2.3 \% ; n=$ 70). In cells that were exposed to a first hypoxic episode of $5 \mathrm{~min}$ duration, we observed conditioning of $35 \pm 9 \sec (n=4 ; p=$ 0.034 , paired $t$ test; data not shown). In 25 cells exposed to two 10 min hypoxic episodes, the majority $(20 ; 80 \%)$ showed a slower rate of decay of the EPSC during the second hypoxic episode $\left(\Delta t_{50}=64 \pm 9 \mathrm{sec}\right)$ (Fig. 4). A small number of the cells $(5 ; 20 \%)$ showed a depression of the EPSC during the second hypoxic episode, which was faster than the depression of the first $\left(\Delta t_{50}=\right.$ $-97 \pm 10 \mathrm{sec}$; data not shown). For both groups there was no significant change in holding current, series resistance, or input resistance between the first and second hypoxic episodes $(p>$ 0.05; paired $t$ test). In addition, the differences between the two groups on the rate of depression of the EPSC during the second hypoxic episode could not be explained in terms of either a difference in any of these parameters or the length of recording ( $p>0.05$; unpaired $t$ test).

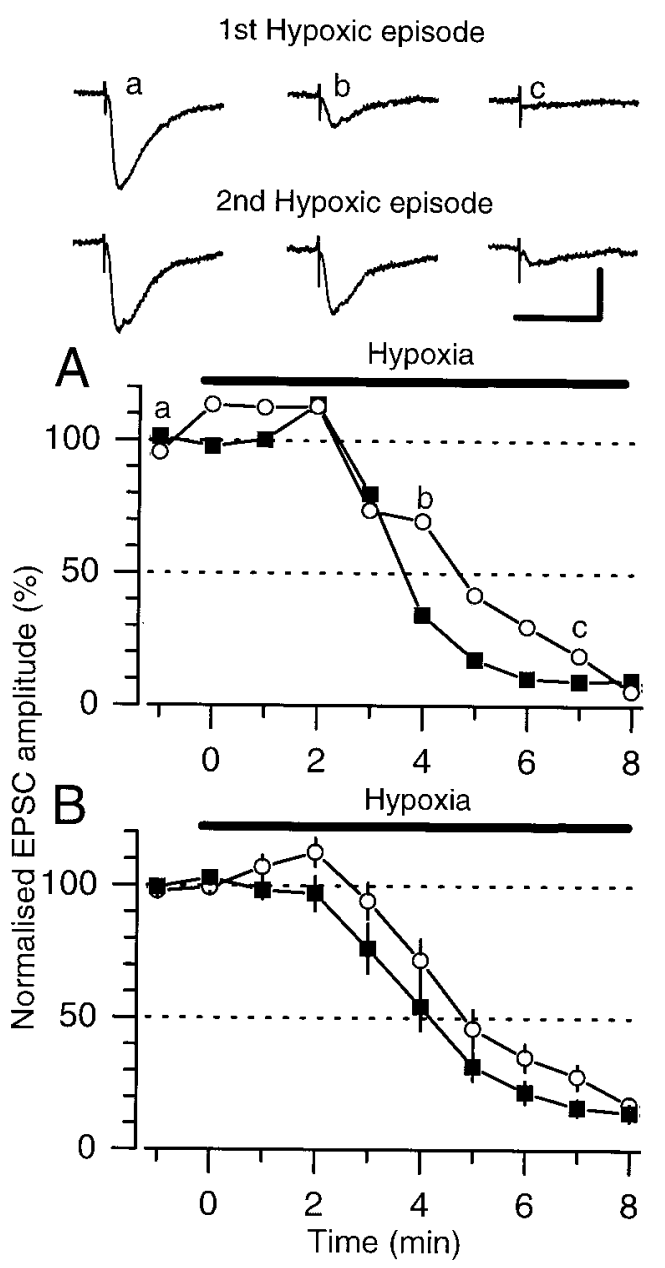

Figure 4. Reduced sensitivity of whole-cell voltage-clamp EPSCs to hypoxia. $A$, Effect of two 10 min periods of hypoxia on EPSC during an individual experiment. Note reduced rate of depression of the EPSC during the second hypoxic episode $(\bigcirc)$ compared with the first $(\square)$. Inset shows EPSCs taken at the times indicated. Calibration: $30 \mathrm{msec}, 50 \mathrm{pA}$. $B$, Pooled data from 20 cells in which cells were exposed to two sequential 10 min periods of hypoxia (first episode, $\mathbf{\square}$; second episode, $\bigcirc$ ). Note increased resistance to the effects of hypoxia during the second hypoxic episode.

\section{Neither impaired adenosine transport nor receptor desensitization is responsible for conditioning}

One mechanism that controls the concentration of extracellular adenosine is the equilibrative adenosine transporter. The delay in the depression of synaptic transmission during the second exposure to hypoxia could reflect an alteration of adenosine transport into or out of the synaptic cleft. We tested this with a combination of adenosine uptake inhibitors: DIPY at $5 \mu \mathrm{M}$ and NBTI at $1 \mu \mathrm{M}$ (cf. Dunwiddie and Diao, 1994). This combination of inhibitors resulted in a profound depression $(67.2 \pm 5.9 \% ; n=8)$ of the fEPSP (Fig. 5A). Indeed in 3/11 slices, synaptic transmission was depressed by $\geq 90 \%$ of control and was not analyzed further. The synaptic depression induced by DIPY/NBTI was fully reversed $(102.3 \pm 10.5 \% ; n=5)$ by the selective $\mathrm{A}_{1}$ antagonist DPCPX (200 nM) (Fig. 5A), indicating the specificity of the depression of transmission by DIPY/NBTI to an accumulation of extracellular adenosine and activation of presynaptic $\mathrm{A}_{1}$ receptors. In five additional experiments (data not shown), this synaptic depression was maintained in the continued presence of DIPY/NBTI for 90 
Figure 5. Conditioning depends on a reduction in extracellular adenosine and not changes in adenosine transport or $\mathrm{A}_{1}$ receptor desensitization. $A$, Incubation with the adenosine transport inhibitors NBTI $(1 \mu \mathrm{M})$ and DIPY $(5 \mu \mathrm{M})$, denoted by bar, greatly depressed the fEPSP $(n=8)$. When the depression had stabilized, two sequential $5 \mathrm{~min}$ hypoxic episodes (each denoted by a bar) were administered. This resulted in a complete depression of synaptic transmission and conditioning of the fEPSP that was no different ( $p=0.82$; unpaired $t$ test) from that in the absence of NBTI/ DIPY (inset histogram; NBTI/DIPY, $n=8$; control, $n=32)$. Application of DPCPX (200 nM; $n=$ 5), denoted by bar, confirmed the NBTI/DIPYinduced depression as being dependent on $\mathrm{A}_{1}$ receptors. Break in time course plot reflects $\sim 30$ min. $B$, Pooled normalized data of fEPSP depressions to two sequential $10 \mathrm{~min}$ applications of 100 $\mu \mathrm{M}$ adenosine on the fEPSP $\left(\Delta t_{50}=1 \pm 3 \mathrm{sec} ; n=\right.$ 6). $C$, Pooled normalized data of fEPSP depressions to hypoxia while in the presence of $10 \mathrm{~nm}$ DPCPX ( $n=7$; $\mathbf{\square}$, first hypoxic episode; $\square$, second hypoxic episode) and for comparison controls ( $n=24$;, first hypoxic episode; $\bigcirc$, second hypoxic episode). For clarity, the shaded bars represent the $\Delta t_{50}$ values for the control experiments (left) and DPCPX experiments (right). Inset is a histogram comparing the magnitude of conditioning in control $(n=94)$ and $10 \mathrm{~nm}$ DPCPX-treated slices $(n=7)$. DPCPX-treated slices exhibited significantly greater conditioning (Student's $t$ test, $p<0.0001$ ), indicating a reduction in extracellular adenosine as the basis of conditioning.


$\min (\sim 75 \%$ depression at $90 \mathrm{~min})$, indicating the lack of significant adenosine washout from the extracellular space.

DIPY/NBTI failed to prevent the hypoxic depression of synaptic transmission $\left(t_{50(1)}=68 \pm 10 \mathrm{sec} ; n=8\right)$. This rate of depression was not significantly different from control $\left(t_{50(1)}=\right.$ $88 \pm 5 \sec ; n=32$; unpaired $t$ test, $p=0.1)$. However, DIPY/ NBTI significantly ( $p<0.01$, unpaired $t$ test) delayed the recovery of synaptic transmission after hypoxia: after $2.25 \mathrm{~min}$ of normoxia the fEPSP had recovered to $50.5 \pm 7.4 \%$ in control aCSF $(n=21)$, whereas at this time transmission had only recovered to $17.1 \pm 3.2 \%$ in DIPY/NBTI $(n=8)$. Moreover, DIPY/NBTI failed to prevent significant conditioning $\left(\Delta t_{50}=\right.$ $29 \pm 8 \mathrm{sec} ; p=0.006$, paired $t$ test; $n=8$ ) or alter its magnitude (unpaired $t$ test, $\mathrm{p}=0.79$ ) when compared with controls (Fig. $5 A$, inset). This indicates first, that reversed adenosine transport may not contribute greatly to the accumulation of adenosine during hypoxia, and second, that impaired adenosine transport does not underlie conditioning. The prolonged exposure to high extracellular levels of endogenous adenosine also suggests that desensitization of $A_{1}$ receptors is unlikely to underlie conditioning.

We further tested the possible role of $A_{1}$ receptor desensitiza- tion by applying exogenous adenosine $(100 \mu \mathrm{M})$ sufficient to almost completely abolish the fEPSP under normoxic conditions (Fig. $5 B$ ). Two sequential applications of $100 \mu \mathrm{M}$ adenosine, each of 10 min duration, resulted in virtually identical rates of depression of the fEPSP $\left(\Delta t_{50}=1 \pm 3 \mathrm{sec} ; n=6\right.$; paired $t$ test, $\left.p>0.22\right)$. Five additional experiments were performed in which two $5 \mathrm{~min}$ applications of $60 \mu \mathrm{M}$ adenosine were interleaved between a 10 and 5 min hypoxic episode (data not shown). In these experiments significant hypoxic conditioning was observed $\left(\Delta t_{(50)}=\right.$ $43 \pm 8 \mathrm{sec} ; n=5$; paired $t$ test, $p<0.006)$, but there was no significant change in the rate at which exogenous adenosine (60 $\mu \mathrm{M})$ depressed the fEPSP $\left(\Delta t_{(50)}=1 \pm 2 \mathrm{sec}\right.$; paired $t$ test, $p>$ $0.7 ; n=5$ ). Our data therefore make it very unlikely that $\mathrm{A}_{1}$ receptor desensitization could underlie conditioning.

\section{Reduced extracellular adenosine underlies conditioning}

Activation of $A_{1}$ receptors on presynaptic glutamatergic terminals largely causes the hypoxic depression of excitatory synaptic transmission in area CA1 (Figs. 1, 3). Conditioning therefore may reflect a reduced rate or amount of adenosine production during 

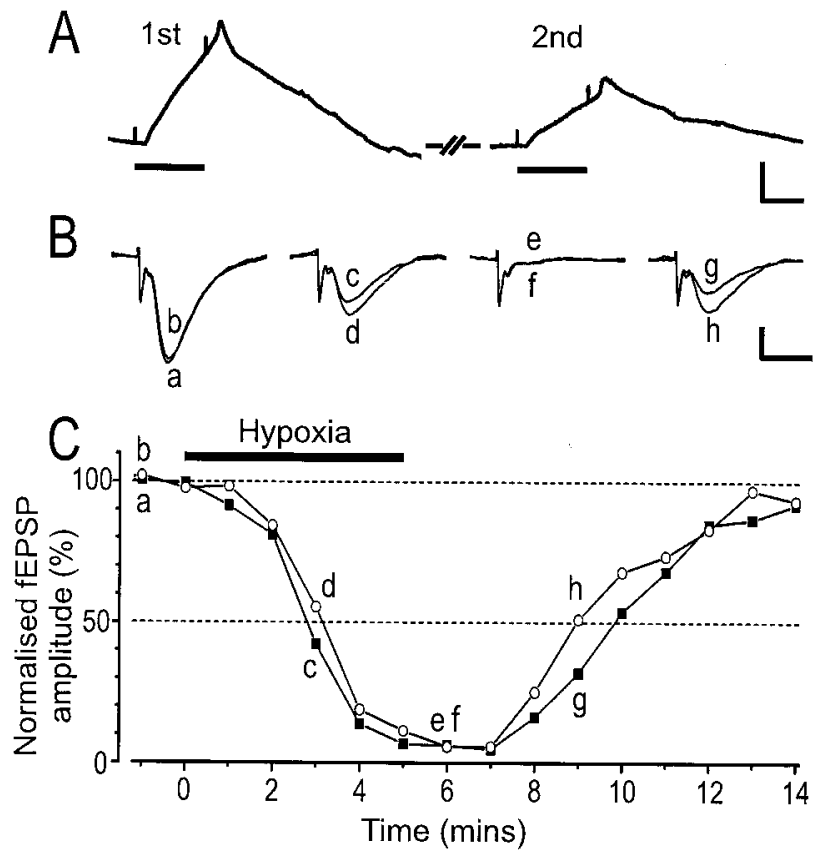

Figure 6. Direct measurement of reduced adenosine release during repeated hypoxia. $A$, Output from the adenosine sensor during two sequential $5 \mathrm{~min}$ periods of hypoxia (black bar and between upward deflections of chart event marker). Note reduced adenosine release during second hypoxic episode. Calibration: $2 \mu \mathrm{M}$ adenosine, $3 \mathrm{~min}$. Break in chart record reflects $\sim 17 \mathrm{~min}$. $B$, Field EPSPs taken at the times indicated in $C$. Calibration: $10 \mathrm{msec}, 0.25 \mathrm{mV}$. $C$, Time course of hypoxic depression of fEPSP showing slower rate of depression ( $c$ vs $d$ ), similar maximal depression ( $e$ vs $f$ ), and more rapid recovery of transmission ( $g$ vs $h$ ) during the second hypoxic episode $(\bigcirc)$ compared with the first (ם).

hypoxia and thus weaker activation of $A_{1}$ receptors. We tested this by using the competitive $\mathrm{A}_{1}$ antagonist DPCPX. If conditioning involved reduced adenosine in the extracellular space during a second hypoxic episode, a low concentration of the competitive antagonist DPCPX should exaggerate conditioning because it will out-compete the lower concentrations of endogenous adenosine that we predict should occur in the synaptic cleft during repeated hypoxia. Because of the partial antagonism of the $A_{1}$ receptors, the rate of depression was significantly slowed in the presence of $10 \mathrm{~nm} \operatorname{DPCPX}\left(t_{50(1)}=252 \pm 44 \mathrm{sec} ; n=7\right)($ Fig. $5 C)$ when

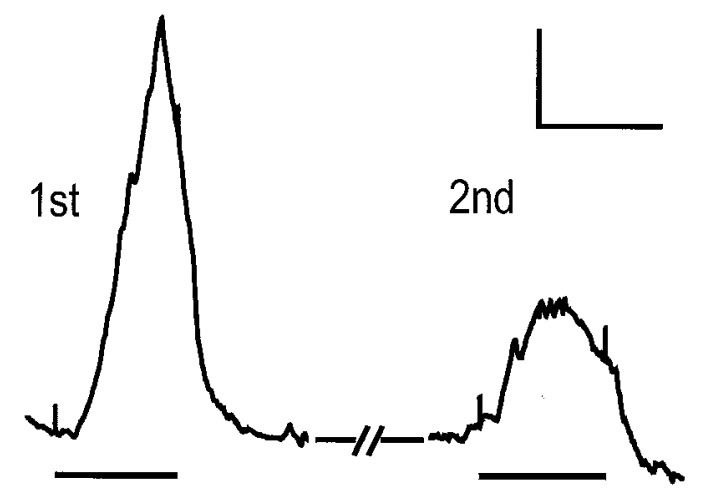

Figure 7. Adenosine depletion in nominally $\mathrm{Ca}^{2+}$-free aCSF. Two sequential 5 min periods of hypoxia (black bars and upward deflections of chart event markers) separated by $30 \mathrm{~min}$ in a slice incubated in nominally $\mathrm{Ca}^{2+}$-free aCSF $\left(2 \mathrm{mM} \mathrm{Ca}^{2+}\right.$ replaced by $\left.2 \mathrm{mM} \mathrm{Mg}^{2+}\right)$ for $>3 \mathrm{hr}$. Note large decrease in adenosine release in response to the second hypoxic episode. Calibration: $5 \mu \mathrm{M}, 5 \mathrm{~min}$.
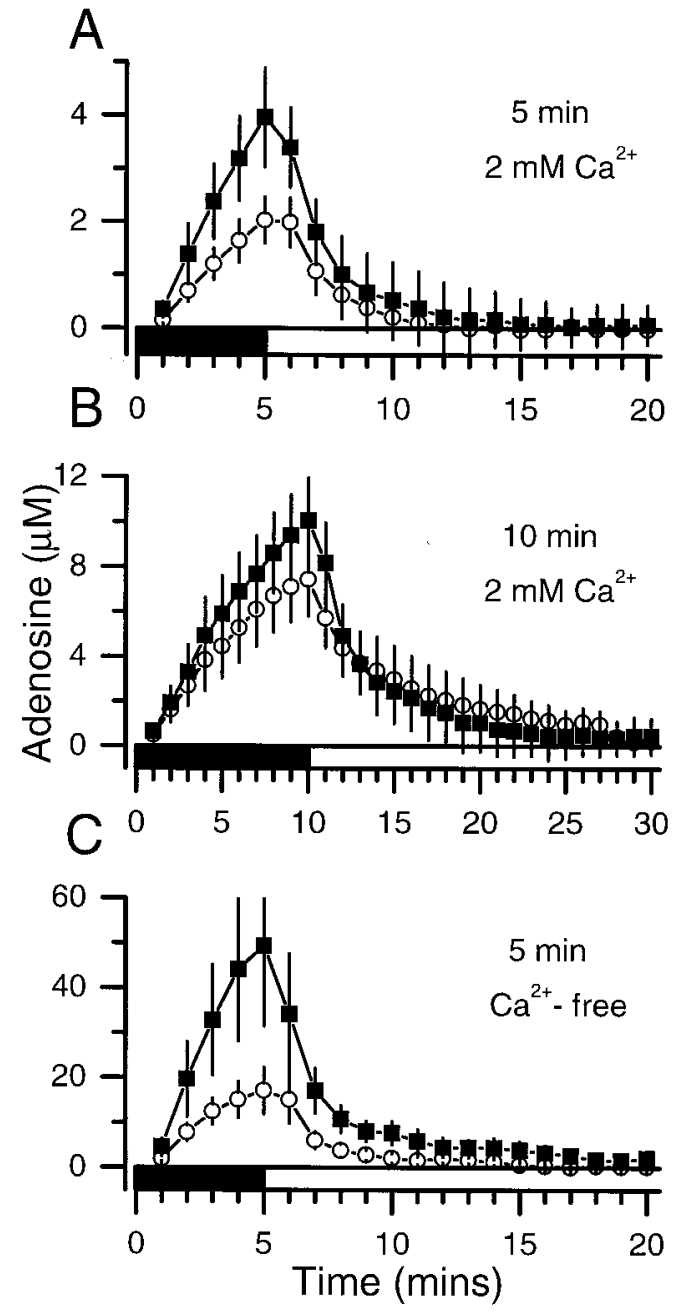

Figure 8. Depletion of adenosine production during successive hypoxic episodes. Pooled data from three different experimental protocols showing the minute-by-minute profile of adenosine release during the first ( $\square$ ) and second $(\bigcirc)$ hypoxic episodes (denoted by black bar). $A$, Two sequential 5 min hypoxic episodes in $2 \mathrm{~mm}$ extracellular $\mathrm{Ca}^{2+}(n=8) ; B$, two sequential $10 \mathrm{~min}$ hypoxic episodes in $2 \mathrm{~mm}$ extracellular $\mathrm{Ca}^{2+}(n=8) ; C$, two sequential $5 \mathrm{~min}$ hypoxic episodes in nominally $\mathrm{Ca}^{2+}$-free aCSF $(2 \mathrm{~mm}$ $\mathrm{Ca}^{2+}$ replaced with $2 \mathrm{mM} \mathrm{Mg}^{2+} ; n=6$ ).

compared with controls $(80 \pm 2$ sec; $n=165 ; p<0.0001$, unpaired $t$ test). However, the depression of the fEPSP during the second hypoxic episode was greatly retarded such that conditioning in the presence of $10 \mathrm{~nm} \mathrm{DPCPX}\left(\Delta t_{50}=119 \pm 38 \mathrm{sec} ; n=\right.$ 7) was significantly greater than in the control $\left(\Delta t_{50}=48 \pm 2 ; n=\right.$ 94; $p<0.0001$, unpaired $t$ test) (Fig. 5C, inset). This result therefore suggests that conditioning reflects reduced adenosine in the synaptic cleft during the second and subsequent hypoxic episodes.

\section{Direct demonstration of reduced extracellular adenosine in response to repeated hypoxia}

Direct measurement of adenosine release confirms the hypothesis that conditioning is associated with reduced adenosine production during repeated hypoxia. Exposure to an initial 5 min hypoxic episode resulted in $3.9 \pm 0.9 \mu \mathrm{M}(n=8)$ adenosine being recorded by the sensor on the surface of the slice. A subsequent 5 min episode delivered $\sim 30$ min later resulted in the release of significantly less adenosine $(2.0 \pm 0.4 \mu \mathrm{M} ; n=8$; paired $t$ test, $p=$ 


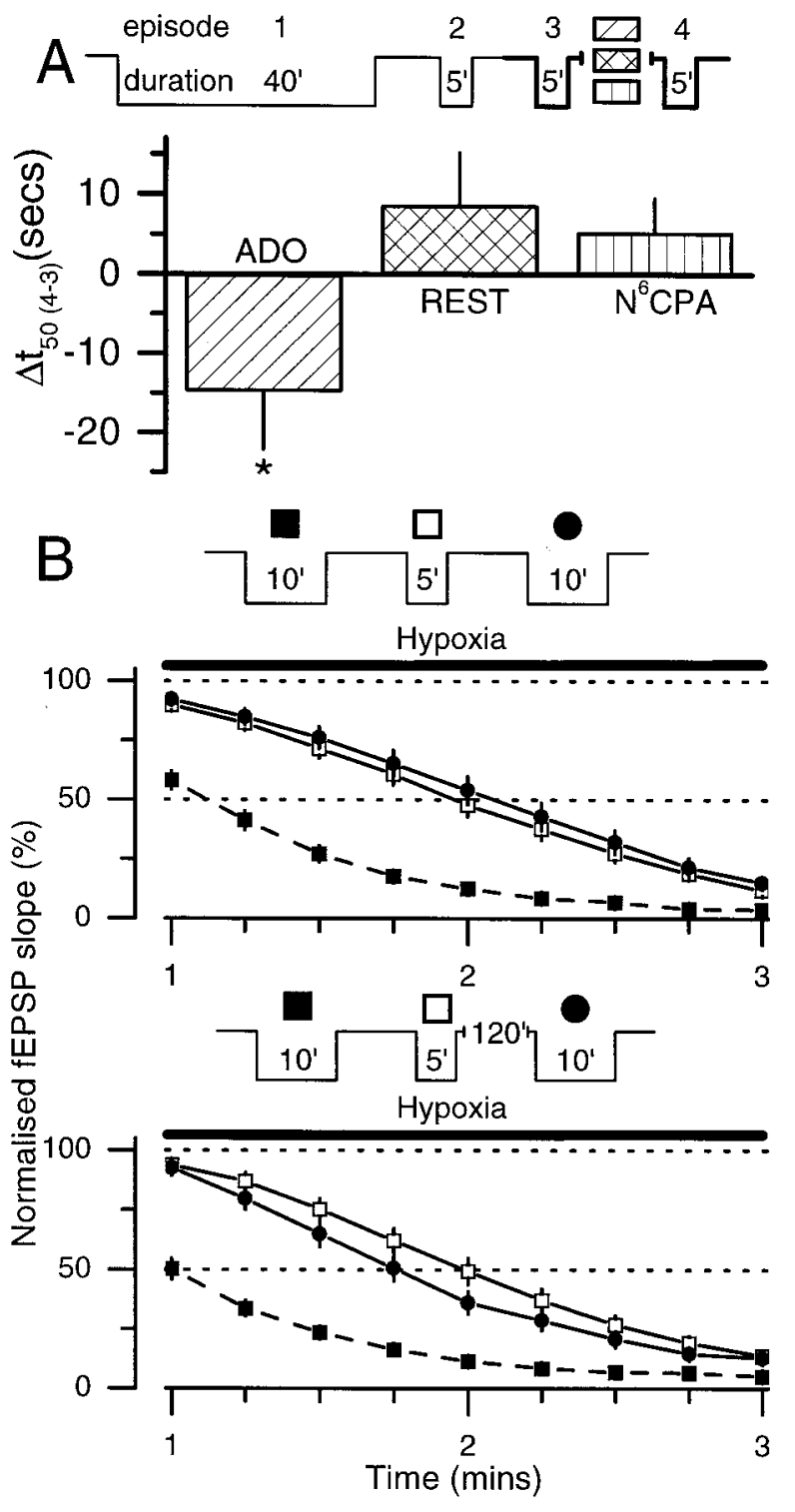

Figure 9. Replenishment of the depleted adenosine. $A$, Exogenous adenosine replenishes the depleted adenosine. After one 40 and two $5 \mathrm{~min}$ hypoxic episodes, slices were exposed to $20 \mu \mathrm{M}$ adenosine $(A D O ; n=10)$ or $30 \mathrm{nM} \mathrm{N}{ }^{6} \mathrm{CPA}\left(N^{6} C P A ; n=9\right)$ or allowed to rest for an equivalent time (15 min; REST; $n=6$ ). A fourth 5 min hypoxic episode was then administered (inset: experimental protocol). A comparison was then made between the $t_{50}$ values of the third and fourth hypoxia-induced depressions of the fEPSP $\left(\Delta t_{50(4-3)}\right.$; in bold in protocol). The bar chart shows that the application of adenosine, but not of the selective $\mathrm{A}_{1}$ agonist $\mathrm{N}^{6} \mathrm{CPA}$ or an equivalent rest period, results in an acceleration of the rate of depression of the fEPSP by hypoxia ( $p<0.05$, unpaired $t$ test). $B$, Replenishment by endogenous adenosine. Experiment in which a 10 (适; dashed line and $5(\square)$ min hypoxic episode was followed by a second 10 (๑) min episode after a short interval $(\sim 10 \mathrm{~min} ; n=13$; top $)$ or after a $2 \mathrm{hr}$ interval $\left(120^{\prime} ; n=13\right.$; bottom). With a short rest, hypoxia causes further conditioning (rightward shift) between the second $(\square)$ and third (-) hypoxic episodes. However, a prolonged rest period of $2 \mathrm{hr}$ between the second $(\square)$ and third $(\bullet)$ hypoxic episodes causes the third exposure to hypoxia to induce a more rapid depression of the fEPSP (leftward shift) throughout the hypoxic episode. These data argue for a replenishment of the depleted adenosine and against gradual deterioration in slice viability.

$0.006)$ (see Fig. $8 A)$. This $49.5 \pm 5 \%(n=8)$ reduction in adenosine release was associated with conditioning of $14 \pm 7 \mathrm{sec}$ (range, $-21-55 \mathrm{sec} ; n=8$ ) (Fig. 6). Experiments in which the first hypoxic episode lasted 10 min caused the release of $9.6 \pm 1.8 \mu \mathrm{M}$ adenosine $(n=9)$. A subsequent $10 \mathrm{~min}$ episode resulted in significantly less adenosine release $(7.0 \pm 1.4 \mu \mathrm{M} ; n=9$; paired $t$ test, $p=0.04$ ) (see Fig. $8 B$ ) and was associated with $27 \pm 6 \mathrm{sec}$ of conditioning (range, $12-68 \mathrm{sec} ; n=9$ ). In these experiments considerable variation was seen in the adenosine released during the second hypoxic episode such that overall the reduction in adenosine release during the second $10 \mathrm{~min}$ hypoxic episode measured $18.6 \pm 10.4 \%$ (range, $-42.1-70.4 \% ; n=9$ ). However, a significant positive correlation $(r=0.7 ; p=0.03 ; n=9)$ was seen between the extent of conditioning and the reduction in adenosine release.

We also observed that hypoxic adenosine production, although not dependent on extracellular calcium (indeed it is inhibited by extracellular calcium) was vulnerable to depletion in nominally calcium-free aCSF (Fig. 7). In these experiments, slices were incubated for 3-6 hr in aCSF in which the calcium was replaced by $2 \mathrm{~mm} \mathrm{Mg}^{2+}$. As reported previously, adenosine production was greatly enhanced during hypoxia under these conditions (Pedata et al., 1993; Dale et al., 2000). The adenosine released during the first 5 min hypoxic episode measured $48.9 \pm 17.7 \mu \mathrm{M}(n=6)$. However, sequential exposure to as little as $5 \mathrm{~min}$ of hypoxia resulted in a massive reduction $(61.4 \pm 7.7 \%)$ in extracellular adenosine during the second hypoxic episode $(16.6 \pm 5.2 \mu \mathrm{M} ; n=$ 6; Wilcoxon matched-pairs signed-ranks test, $p=0.028$ ) (Fig. 8C). This reduction was not caused by nonspecific cellular deterioration of the slice because the fEPSP returned when perfused with standard $2 \mathrm{mM} \mathrm{Ca}^{2+}$-containing aCSF (data not shown).

\section{Restoration of adenosine release}

We attempted to restore depleted levels of adenosine release by perfusing slices with exogenous adenosine. In this series of experiments, conditioning and depletion of adenosine release were induced by an initial $40 \mathrm{~min}$ hypoxic episode. This was followed by two 5 min test periods of hypoxia to measure the extent of conditioning, and then perfusion with $20 \mu \mathrm{M}$ adenosine for 15 min to attempt to restore or replenish the levels of adenosine production (Fig. 9A). A final 5 min test period of hypoxia after adenosine washout was administered to measure the extent of conditioning before and after the attempted replenishment. A time control was conducted in an interleaved series of experiments in which no adenosine was perfused between the third and fourth hypoxic episodes (Fig. 9A). A further control specifically for $\mathrm{A}_{1}$ receptor activation, perfusion with the metabolically stable adenosine analog $30 \mathrm{~nm} \mathrm{~N}{ }^{6} \mathrm{CPA}$ (Fig. 9A), was also interleaved. The exogenous application of adenosine resulted in replenishment of adenosine release, seen as a significant reversal of conditioning between the third and final hypoxic episodes $\left(\Delta t_{50}=\right.$ $-15 \pm 7 \mathrm{sec} ; n=10 ; p<0.05$, unpaired $t$ test). In contrast, both the time control and the $30 \mathrm{~nm} \mathrm{~N}^{6} \mathrm{CPA}$ experiments exhibited additional adenosine depletion seen as a further increase in conditioning $\left(\Delta t_{50}=9 \pm 7 \mathrm{sec} ; n=6\right.$ and $5 \pm 4$ and $n=9$, respectively).

We next determined whether the slice had the capacity to restore adenosine release from endogenous sources. This homeostatic mechanism must be slow because there was no significant difference ( $p>0.9$; unpaired $t$ test) in conditioning between slices exposed to a $10 \mathrm{~min}$ hypoxic episode with a brief ( $\sim 12 \mathrm{~min}$; $\left.\Delta t_{50}=48 \pm 2 \mathrm{sec} ; n=94\right)$ inter-episode interval and slices in which the inter-episode interval was of intermediate duration (45 min; $\left.\Delta t_{50}=48 \pm 10 \mathrm{sec} ; n=10\right)$. This suggests that a single exposure to hypoxia can influence the subsequent hypoxic de- 
pression of synaptic transmission for a considerable length of time and further argues against a gradual deterioration in slice viability as the basis of conditioning.

We therefore examined whether replenishment from endogenous sources might occur over a longer time scale by using another experimental protocol in which three hypoxic episodes were administered (Fig. 9B). The first two episodes allowed measurement of the extent of conditioning within each slice. The third episode, given after a delay of either $\sim 10$ or $120 \mathrm{~min}$, allowed the comparison of the influence of the protracted rest period on the rate of hypoxic depression of the fEPSP. In the control group, slices were exposed to two hypoxic episodes of 10 and 5 min duration and then left to recover for only $\sim 10 \mathrm{~min}$ before retesting with another hypoxic episode $(10 \mathrm{~min})$. These slices showed further conditioning on either side of the $10 \mathrm{~min}$ rest period $\left(\Delta t_{50(3-2)}=6 \pm 4 \mathrm{sec} ; n=13\right)$. In the experimental group, slices were allowed to recover for $120 \mathrm{~min}$ between the second and third hypoxic episodes. In direct contrast to the controls, these slices showed an acceleration in the rate at which hypoxia depressed synaptic transmission on either side of the rest period $\left(\Delta t_{50(3-2)} ;-12 \pm 7 \mathrm{sec} ; n=13 ; p=0.03\right.$ vs control, unpaired $t$ test). The accelerated rate of depression after the rest period suggests that the slice is able, albeit rather slowly, to replenish adenosine release from endogenous sources. Furthermore, our results indicate that it is possible to observe and study this potentially important process of replenishment in vitro.

\section{DISCUSSION}

\section{A depletable pool of adenosine: a working model}

We have documented that with repeated episodes of hypoxia, the levels of adenosine production fall. This observation could result from a weakening of the release process itself, which may include some change in the intracellular formation of adenosine, a strengthening of reuptake mechanisms or, if adenosine is not released directly, a weakening of ectoenzyme activity. One distinct possibility is that the weakening of adenosine production reported here reflects depletion of adenine nucleotides (cf. Siesjo and Wieloch, 1985). We cannot discriminate among these possibilities at this stage, but our experiments with the uptake inhibitors DIPY and NBTI make changes in reuptake unlikely. We propose the existence of a depletable pool of adenosine or precursor as being the simplest interpretation of our findings. This pool is accessed by metabolic stress, in our case hypoxia, which results in reduced availability of adenosine for a considerable time thereafter. During this time a subsequent hypoxic episode is less effective at depressing excitatory synaptic transmission. In the young rats used in this study, the slowing of the depression of excitatory transmission depends critically on the severity of the initial hypoxic episode but can be observed at both the population (field recordings) and single-cell level (patch-clamp recordings). Because the neuronal response to metabolic stress varies with age (Cherubini et al., 1989; Yager and Thornhill, 1997), it remains to be seen whether adenosine depletion also varies with maturation. Because the contributions from CA3 neurons, GABAergic inhibition, and postsynaptic depolarization were removed or controlled for in the patch-clamp experiments, these mechanisms are unlikely to contribute to the changes in rate of synaptic depression seen with repeated hypoxia.

Although the dramatic enhancement of hypoxic/ischemic adenosine release in calcium-free medium has been demonstrated previously (Pedata et al., 1993; Dale et al., 2000), we have shown that the depletion of adenosine is particularly extensive in nom- inally calcium-free aCSF. This may reflect the greatly enhanced release or a calcium-dependency of replenishment. The mechanism underlying the increased release and depletion during hypoxia in nominally calcium-free aCSF is unclear, but it does not rely on gross pathological cell lysis because synaptic transmission indistinguishable from control was obtained on perfusion with normal calcium-containing aCSF. Local reductions in extracellular calcium (Rusakov et al., 1999) during repetitive synaptic or seizure activity or during hypoxia/ischemia may influence the rate at which the adenosine pool is released (Dale et al., 2000), depleted, or replenished.

\section{Replenishment of adenosine release}

An important finding of our study is that replenishment of adenosine release is possible by both endogenous and exogenous mechanisms. The former likely exploits mechanisms within the CNS to either sequester ambient adenosine or synthesize adenosine from precursors. The latter offers scope for exogenous, therapeutic intervention in conditions ameliorated by adenosine. The extent of endogenous replenishment is slow and weak under the present circumstances, but the fact that it can be observed at all indicates that depletion is not a progressive deterioration in the viability of the slice. Furthermore, it indicates that conditioning does not merely reflect nonspecific washout of adenosine from the slice, because $t_{50}$ remained stable over time, transmission remained fully depressed for the 40 min duration of the hypoxic episode [see also Arlinghaus and Lee (1996)], and prolonged (90 min) incubation in uptake inhibitors resulted in a sustained depression of transmission.

\section{Purine loss from the CNS in vivo}

An important issue is the extent to which the adenosine loss we have described in vitro occurs in vivo. Reduced release of adenosine after repeated global ischemia at $2 \mathrm{hr}$ intervals was observed in an in vivo microdialysis study (Valtysson et al., 1998). The same study reported the enhanced production of xanthine after ischemia, which, as a nonsalvageable product of purine metabolism, represents a source of adenosine loss. These findings may reflect the depletion of adenine nucleotides after metabolic stress and the slow nature of their synthesis such that energy charge is reestablished several hours before the nucleotide pool is restored (Siesjo and Wieloch, 1985). Furthermore, the very high density of equilibrative adenosine transporters in the mammalian bloodbrain barrier (Kalaria and Harik, 1986) implies that increases in intracerebral adenosine are cleared rapidly and that the CNS may actually lose adenosine to the systemic circulation in vivo. Indeed, several clinical studies have measured sustained increases in systemic blood adenosine levels in humans suffering from stroke and transient ischemic attack (Laghi-Pasini et al., 2000) or experiencing cerebral ischemia during carotid endarterectomy (Weigand et al., 1999). Although our in vitro model may not reflect all aspects of adenosine depletion in vivo, it does allow the consequences of adenosine depletion for neuronal function to be studied directly and in isolation.

\section{Implications for neuroprotection by adenosine}

The vital modulatory role of adenosine in the mammalian CNS extends to its accumulation during periods of metabolic or traumatic stress (Rudolphi et al., 1992; Sweeney, 1997; Von Lubitz, 1999). It is therefore surprising and counterintuitive to discover that this vital role can be compromised by a brief exposure to sublethal hypoxia or ischemia. The functional ramifications of this are manifold and serious. In the first instance, as presented 
here, excitatory glutamatergic transmission will persist for longer during hypoxia/ischemia. This will allow potentially pathological activation of postsynaptic glutamate receptors at a time when the ATP production necessary to maintain neuronal integrity is compromised. In addition, the postsynaptic hyperpolarization mediated by adenosine will be lessened. Thus, reduced adenosine in the synaptic cleft favors increased glutamate release, postsynaptic depolarization, glutamate receptor activation, and postsynaptic calcium influx during both the onset of metabolic stress and reperfusion. In addition, a reduction in CNS adenosine will result in less vasodilatation of the cerebral vasculature reducing oxygen/ glucose delivery to the brain. In total, the implications of a reduction in adenosine availability are likely to have serious consequences for the intact brain, a plausible explanation for the increased sensitivity of the in vivo brain to repeated brief hypoxia/ischemia.

Many studies have found that repeated sublethal episodes (2-3 min) greatly exacerbate the biochemical changes associated with hypoxia/ischemia (Mrsulja et al., 1977), including increased calcium accumulation within neurons (Kato et al., 1989), and initiate destruction of selectively vulnerable neurons in area CA1, striatum, and thalamus (Kato et al., 1989; Kato and Kogure, 1990), resulting in infarction (Kato et al., 1992). Because NMDA receptor antagonists prevent the neuronal death associated with repeated brief ischemia (Kato et al., 1990), increases in extracellular glutamate may underlie this phenomenon. However, the evidence is contradictory regarding whether repeated brief ischemia augments glutamate release (Lin et al., 1992; Nakata et al., 1992). The mechanism that we propose, of reduced adenosine release, would accommodate either scenario because even the same amount of glutamate release would be expected to result in greater neuropathology.

In vivo maximal vulnerability occurs $1 \mathrm{hr}$ after the initial hypoxic/ischemic episode. At this time, minimal replenishment of the adenosine pool would be expected. However, at shorter intervals, extracellular levels of adenosine may still be elevated (Valtysson et al., 1998) and, in tandem with depressed excitatory synaptic transmission, may promote neuroprotection (PerezPinzon et al., 1997; Stagliano et al., 1999). At longer intervals ( $>4$ hr), adenosine levels may be at least partially replenished. Even longer inter-episode intervals $(24 \mathrm{hr})$ give rise to ischemic preconditioning (Chen and Simon, 1997) wherein neuropathology is reduced. Given the long delay before protective preconditioning is seen in vivo and the requirement for protein synthesis, the extent to which protective preconditioning can be studied in vitro, over the time course of the present experiments, is questionable. Studies reporting a more rapid and complete recovery or potentiations of transmission after brief ischemia in vitro may reflect a reduction in extracellular adenosine rather than the induction of a protective mechanism applicable to the in vivo situation.

In addition to offering an explanation for the increased vulnerability of the brain after hypoxia/ischemia, the concept of a depletable pool of CNS adenosine provides a plausible basis for the sensitization of brain tissue after head injury or after status epilepticus. Both cause adenosine release that if lost, either to the systemic circulation (Weigand et al., 1999; Laghi-Pasini et al., 2000) or to nonsalvageable xanthine (Valtysson et al., 1998), would compromise the ability of the brain to protect itself during subsequent hypoxia/ischemia. That these conditions do indeed result in the diminished availability of adenosine is supported by reduced hypoxic vasodilatation after status epilepticus [which has been proposed to involve less adenosine release (DiGeronimo et al., 1998)] and the reduced cerebral blood flow after head injury (Lewelt et al., 1982). Indeed, entry into status epilepticus may result from an attenuation or loss of adenosinergic tone after previous seizure activity (Young and Dragunow, 1994).

Our findings provide direct evidence for the existence of a depletable, but replenishable, pool of adenosine in the mammalian CNS. The actual nature of the pool remains to be clarified but may involve adenosine per se, a precursor, or an enzyme or transport system, ultimately resulting in the accumulation of adenosine in the extracellular space. The ability to investigate this pool in vitro offers the opportunity to explore novel therapeutic avenues relating to various human clinical conditions in which intervention may reduce the severity of secondary central metabolic stress.

\section{REFERENCES}

Arlinghaus L, Lee KS (1996) Endogenous adenosine mediates the sustained inhibition of excitatory synaptic transmission during moderate hypoxia. Brain Res 724:265-268.

Berne RM, Rubio R, Curran GH (1974) Release of adenosine from ischemic brain. Circ Res 35:262-271.

Blumbergs PC (1997) Pathology. In: Head injury: pathophysiology and management of severe closed injury (Reilly P, Bullock R, eds), pp 40-70. London: Chapman \& Hall.

Chen J, Simon R (1997) Ischemic tolerance in the brain. Neurology 48:306-311.

Cherubini E, Ben-Ari Y, Krnjevic K (1989) Anoxia produces smaller changes in synaptic transmission, membrane potential, and input resistance in immature rat hippocampus. J Neurophysiol 62:882-895.

Dale N (1998) Delayed production of adenosine underlies temporal modulation of swimming in frog embryo. J Physiol (Lond) 511:265-272.

Dale N, Pearson T, Frenguelli BG (2000) Direct measurement of adenosine release during hypoxia in the CA1 region of the rat hippocampal slice. J Physiol (Lond) 526:143-155.

de Mendonca A, Sebastiao AM, Ribeiro JA (2000) Adenosine: does it have a neuroprotective role after all? Brain Res Rev 33:258-274.

DiGeronimo RJ, Gegg CA, Zuckerman SL (1998) Adenosine depletion alters postictal hypoxic cerebral vasodilation in the newborn pig. Am J Physiol 274:H1495-H1501.

Donaghy KM, Scholfield CN (1994) Concentration dependence of adenosine and the protection of rat cortical neurones during anoxia. Brain Res 656:174-176.

Dunwiddie TV (1999) Adenosine and suppression of seizures. Adv Neurol 79:1001-1010.

Dunwiddie TV, Diao L (1994) Extracellular adenosine concentrations in hippocampal brain slices and the tonic inhibitory modulation of evoked excitatory responses. J Pharmacol Exp Ther 268:537-545.

Erdemli G, Xu YZ, Krnjevic K (1998) Potassium conductance causing hyperpolarization of CA1 hippocampal neurons during hypoxia. J Neurophysiol 80:2378-2390.

Fowler JC (1989) Adenosine antagonists delay hypoxia-induced depressions of neuronal activity in hippocampal brain slice. Brain Res 490:378-384.

Frenguelli BG (1997) The effects of metabolic stress on glutamate receptor-mediated depolarisations in the in vitro rat hippocampal slice. Neuropharmacology 36:981-991.

Gidday JM, Fitzgibbons JC, Shah AR, Kraujalis MJ, Park TS (1995) Reduction in cerebral ischemic injury in the newborn rat by potentiation of endogenous adenosine. Pediatr Res 38:306-311.

Headrick JP, Bendall MR, Faden AI, Vink R (1994) Dissociation of adenosine levels from bioenergetic state in experimental brain trauma: potential role in secondary injury. J Cereb Blood Flow Metab $14: 853-861$.

Jenkins LW, Moszynski K, Lyeth BG, Lewelt W, DeWitt DS, Allen A, Dixon CE, Povlishock JT, Majewski TJ, Clifton GL (1989) Increased vulnerability of the mildly traumatized rat brain to cerebral ischemia: the use of controlled secondary ischemia as a research tool to identify common or different mechanisms contributing to mechanical and ischemic brain injury. Brain Res 477:211-224.

Jiang N, Kowaluk EA, Lee CH, Mazdiyasni H, Chopp M (1997) Adenosine kinase inhibition protects brain against transient focal ischemia in rats. Eur J Pharmacol 320:131-137.

Kalaria RN, Harik SI (1986) Nucleoside transporter of cerebral microvessels and choroid plexus. J Neurochem 47:1849-1856.

Katchman AN, Hershkowitz N (1993) Adenosine antagonists prevent hypoxia-induced depression of excitatory but not inhibitory synaptic currents. Neurosci Lett 159:123-126.

Kato H, Kogure K (1990) Neuronal damage following non-lethal but 
repeated cerebral ischemia in the gerbil. Acta Neuropathol (Berl) 79:494-500.

Kato H, Kogure K, Nakano S (1989) Neuronal damage following repeated brief ischemia in the gerbil. Brain Res 479:366-370.

Kato H, Araki T, Kogure K (1990) Role of the excitotoxic mechanism in the development of neuronal damage following repeated brief cerebral ischemia in the gerbil: protective effects of MK-801 and pentobarbital. Brain Res 516:175-179.

Kato H, Araki T, Kogure K (1992) Repeated focal cerebral ischemia in gerbils is associated with development of infarction. Brain Res 596:315-319.

Laghi-Pasini F, Guideri F, Picano E, Parenti G, Petersen C, Varga A, Di Perri $T$ (2000) Increase in plasma adenosine during brain ischemia in man: a study during transient ischemic attacks, and stroke. Brain Res Bull 51:327-330.

Lewelt W, Jenkins LW, Miller JD (1982) Effects of experimental fluidpercussion injury of the brain on cerebrovascular reactivity of hypoxia and to hypercapnia. J Neurosurg 56:332-338.

Lin B, Globus MY, Dietrich WD, Busto R, Martinez E, Ginsberg MD (1992) Differing neurochemical and morphological sequelae of global ischemia: comparison of single- and multiple-insult paradigms. J Neurochem 59:2213-2223.

Miller LP, Jelovich LA, Yao L, DaRe J, Ugarkar B, Foster AC (1996) Pre- and peristroke treatment with the adenosine kinase inhibitor, 5 '-deoxyiodotubercidin, significantly reduces infarct volume after temporary occlusion of the middle cerebral artery in rats. Neurosci Lett 220:73-76.

Mrsulja BB, Lust WD, Mrsulja BJ, Passonneau JV (1977) Effect of repeated cerebral ischemia on metabolites and metabolic rate in gerbil cortex. Brain Res 119:480-486.

Nakata N, Kato H, Liu Y, Kogure K (1992) Effects of pretreatment with sublethal ischemia on the extracellular glutamate concentrations during secondary ischemia in the gerbil hippocampus evaluated with intracerebral microdialysis. Neurosci Lett 138:86-88.

Nawashiro H, Shima K, Chigasaki H (1995) Selective vulnerability of hippocampal CA3 neurons to hypoxia after mild concussion in the rat. Neurol Res 17:455-460.

Newby AC (1984) Adenosine and the concept of retaliatory metabolites. Trends Biochem Sci 9:42-44.

Nilsson P, Hillered L, Ponten U, Ungerstedt U (1990) Changes in cortical extracellular levels of energy-related metabolites and amino acids following concussive brain injury in rats. J Cereb Blood Flow Metab 10:631-637.

Pearson T, Frenguelli BG (2000) Volume-regulated anion channels do not contribute extracellular adenosine during the hypoxic depression of excitatory synaptic transmission in area CA1 of rat hippocampus. Eur J Neurosci 12:3064-3066.
Pedata F, Latini S, Pugliese AM, Pepeu G (1993) Investigations into the adenosine outflow from hippocampal slices evoked by ischemia-like conditions. J Neurochem 61:284-289.

Perez-Pinzon MA, Xu GP, Dietrich WD, Rosenthal M, Sick TJ (1997) Rapid preconditioning protects rats against ischemic neuronal damage after 3 but not $7 \mathrm{~d}$ of reperfusion following global cerebral ischemia. J Cereb Blood Flow Metab 17:175-182.

Phillis JW, O'Regan MH (1989) Deoxycoformycin antagonizes ischemiainduced neuronal degeneration. Brain Res Bull 22:537-540.

Rudolphi KA, Schubert P, Parkinson FE, Fredholm BB (1992) Neuroprotective role of adenosine in cerebral ischaemia. Trends Pharmacol Sci 13:439-445.

Rusakov DA, Kullmann DM, Stewart MG (1999) Hippocampal synapses: do they talk to their neighbours? Trends Neurosci 22:382-388.

Siesjo BK, Wieloch T (1985) Cerebral metabolism in ischaemia: neurochemical basis for therapy. Br J Anaesth 57:47-62.

Stagliano NE, Perez-Pinzon MA, Moskowitz MA, Huang PL (1999) Focal ischemic preconditioning induces rapid tolerance to middle cerebral artery occlusion in mice. J Cereb Blood Flow Metab 19:757-761.

Sweeney MI (1997) Neuroprotective effects of adenosine in cerebral ischemia: window of opportunity. Neurosci Biobehav Rev 21:207-217.

Tomida S, Nowak Jr TS, Vass K, Lohr JM, Klatzo I (1987) Experimental model for repetitive ischemic attacks in the gerbil: the cumulative effect of repeated ischemic insults. J Cereb Blood Flow Metab 7:773-782.

Valtysson J, Persson L, Hillered L (1998) Extracellular ischaemia markers in repeated global ischaemia and secondary hypoxaemia monitored by microdialysis in rat brain. Acta Neurochir (Wien) 140:387-395.

Volpe JJ (1995) Neonatal seizures. In: Neurology of the newborn (Volpe JJ, ed), pp 172-184. Philadelphia: Saunders.

Von Lubitz DKJE (1999) Adenosine and cerebral ischemia: therapeutic future or death of a brave concept? Eur J Pharmacol 365:9-25.

Weigand MA, Michel A, Eckstein HH, Martin E, Bardenheuer HJ (1999) Adenosine: a sensitive indicator of cerebral ischemia during carotid endarterectomy. Anesthesiology 91:414-421.

Winn HR, Welsh JE, Rubio R, Berne RM (1980) Changes in brain adenosine during bicuculline-induced seizures in rats. Effects of hypoxia and altered systemic blood pressure. Circ Res 47:568-577.

Yager JY, Thornhill JA (1997) The effect of age on susceptibility to hypoxic-ischemic brain damage. Neurosci Biobehav Rev 21:167-174.

Young D, Dragunow M (1994) Status epilepticus may be caused by loss of adenosine anticonvulsant mechanisms. Neuroscience 58:245-261.

Zhu PJ, Krnjevic K (1993) Adenosine release is a major cause of failure of synaptic transmission during hypoglycaemia in rat hippocampal slices. Neurosci Lett 155:128-131. 